\title{
Hemodynamic and clinical onset in patients with hereditary pulmonary arterial hypertension and BMPR2 mutations
}

Nicole Pfarr ${ }^{1,2 \dagger}$, Justyna Szamalek-Hoegel ${ }^{2 \dagger}$, Christine Fischer ${ }^{2 \dagger}$, Katrin Hinderhofer ${ }^{2}$, Christian Nagel ${ }^{1}$, Nicola Ehlken ${ }^{1}$, Henning Tiede ${ }^{3}$, Horst Olschewski ${ }^{4}$, Frank Reichenberger ${ }^{3}$, Ardeschir HA Ghofrani ${ }^{3}$, Werner Seeger ${ }^{3}$ and Ekkehard Grünig ${ }^{*^{*}}$

\begin{abstract}
Background: Mutations in the bone morphogenetic protein receptor 2 (BMPR2) gene can lead to idiopathic pulmonary arterial hypertension (IPAH). This study prospectively screened for BMPR2 mutations in a large cohort of PAH-patients and compared clinical features between BMPR2 mutation carriers and non-carriers.

Methods: Patients have been assessed by right heart catheterization and genetic testing. In all patients a detailed family history and pedigree analysis have been obtained. We compared age at diagnosis and hemodynamic parameters between carriers and non-carriers of BMPR2 mutations. In non-carriers with familial aggregation of PAH further genes/gene regions as the BMPR2 promoter region, the ACVRL1, Endoglin, and SMAD8 genes have been analysed.
\end{abstract}

Results: Of the 231 index patients 22 revealed a confirmed familial aggregation of the disease (HPAH), 209 patients had sporadic IPAH. In 49 patients (86.3\% of patients with familial aggregation and $14.3 \%$ of sporadic IPAH) mutations of the BMPR2 gene have been identified. Twelve BMPR2 mutations and 3 unclassified sequence variants have not yet been described before. Mutation carriers were significantly younger at diagnosis than non-carriers ( $38.53 \pm 12.38$ vs. $45.78 \pm 11.32$ years, $p<0.001)$ and had a more severe hemodynamic compromise. No gene defects have been detected in 3 patients with HPAH.

Conclusion: This study identified in a large prospectively assessed cohort of PAH- patients new BMPR2 mutations, which have not been described before and confirmed previous findings that mutation carriers are younger at diagnosis with a more severe hemodynamic compromise. Thus, screening for BMPR2 mutations may be clinically useful.

\section{Introduction}

Pulmonary arterial hypertension $(\mathrm{PAH})$ is a rare vascular disorder characterised by increased pulmonary vascular resistance and right heart failure. PAH can be idiopathic (IPAH), heritable (HPAH) or associated with other conditions (APAH) as connective tissue diseases, congenital heart diseases, portal hypertension, drug or toxin exposure $[1,2]$. Heterozygous germline mutations in the bone morphogenetic protein type 2 receptor (BMPR2) have

\footnotetext{
* Correspondence: ekkehard.gruenig@thoraxklinik-heidelberg.de

+ Contributed equally

${ }^{1}$ Centre for Pulmonary Hypertension Thoraxclinic, University of Heidelberg, Heidelberg, Germany

Full list of author information is available at the end of the article
}

been identified as a gene underlying HPAH in approximately 10 to $40 \%$ of patients with apparently sporadic disease $[1,3-6]$ and in $58 \%$ to $74 \%$ of patients with familial PAH $[1,4,6,7]$. In total 298 different mutations in $B M P R 2$ have been identified so far in independent patients including those with a known PAH family history, sporadic disease and PAH associated with other diseases [1]. In a few PAH patients mutations in other genes participating in the BMPR2 signalling pathway have been identified, as Activin A receptor type II-like 1 (ACVRL1, also called ALK1) [8], Endoglin [9], and SMAD8 [10]. Nevertheless, there is still a small

\section{Biomed Central}

(c) 2011 Pfarr et al; licensee BioMed Central Ltd. This is an Open Access article distributed under the terms of the Creative Commons Attribution License (http://creativecommons.org/licenses/by/2.0), which permits unrestricted use, distribution, and reproduction in any medium, provided the original work is properly cited. 
proportion of patients with familial aggregation of $\mathrm{PAH}$ in which no gene defects can be detected so far $[7,11]$.

HPAH patients carrying a BMPR2 mutation develop the disease approximately 10 years earlier than non-carriers, with more severe hemodynamic changes [6,12-15] and a reduced response to acute vasodilator testing [6,12,14-16]. Patients carrying ACVRL1 or Endoglin mutations have been characterised to be of younger age at diagnosis and death as patients without mutations [14]. A recent study of Austin et al [17] showed that HPAH female patients with missense mutations in the BMPR2 gene had a more severe disease than patients with truncating mutations. These publications indicate that the clinical phenotype of PAH can be affected by the type of mutation. However, most data comparing clinical features between BMPR2 mutation carriers and non-carriers have been obtained from registries as from the French Network of Pulmonary Hypertension [6,13-15], and from centres in the United States as the New York Presbyterian Pulmonary Hypertension Center [12], the Utah Pulmonary Hypertension Genetics Project [16] or the Vanderbilt University School of Medicine, Nashville, Tennessee $[7,17,18]$ and are retrospective in design. The genetic mechanism of $\mathrm{PAH}$ remains unclear in those families in which no BMPR2 mutation can be detected.

Therefore, the aim of this study was to evaluate hemodynamic parameters and genetic status in a large German cohort of patients using a prospective design. The frequency of known BMPR2 mutations has been analysed and a detailed search for new BMPR2 mutations has been performed. In this study, we present 12 new BMPR2 mutations and 3 unclassified variants which have not been described before. Furthermore, we describe the clinical features of families with confirmed familial aggregation of PAH but no detectable mutations of the BMPR2 gene and tested these families for mutations of the genes ACVRL1, Endoglin, and SMAD8.

\section{Materials and methods Study Population}

This prospective study investigated adult patients $(\geq 18$ years) with confirmed sporadic IPAH or familial HPAH between January 2006 and December 2009, who agreed to a genetic testing and from whom EDTA-blood was obtained. Patients have been seen in the centres of pulmonary hypertension $(\mathrm{PH})$ of Heidelberg and Giessen and underwent complete clinical and genetic work-up. In all patients a right heart catheterization and a detailed family history was obtained and a three to four generation pedigree was constructed. For deceased relatives, medical records were reviewed when available and the diagnosis of PAH was based on the criteria used for index patients as well as on the results of the post mortem examination. Familial disease has been postulated when PAH was diagnosed in at least two family members. Sporadic IPAH was stated when family history and medical records of family members were negative.

The Ethics Committees of the Medical Faculties of the Universities of Heidelberg and Giessen approved the protocol of this study, and the family members gave their written informed consent. All participating patients and family members underwent genetic counselling. The study was part of the European Projects "Pulmotension" which belongs to the 6th European Framework.

\section{Mutation analysis of the BMPR2 gene}

EDTA-blood samples were collected for genetic analysis in all patients and from all family members, if available. Human genomic DNA was prepared from peripheral blood lymphocytes. The complete coding sequence and exon/intron boundaries of the BMPR2 gene from each individual were amplified and analysed by DHPLC and/ or direct sequencing as previously described [4]. HPAH patients without an obvious BMPR2 mutation were also analysed for mutations in the $B M P R 2$ promoter, the ACVRL1 gene, Endoglin gene, and SMAD8 gene. In $\mathrm{HPAH}$ cases all first degree relatives were investigated for the mutation identified in the index patient. Primer sequences and PCR conditions are available upon request. Standard DNA sequencing reactions were performed using version 1.1 of Big Dye terminator cycle sequencing kit (Applied Biosystems Inc., Darmstadt) and were analysed on a Genetic Analyzer 3100 (Applied Biosystems Inc., Darmstadt). Pathogenicity of identified sequence alterations were assessed by use of the program MutationTaster http://www.mutationtaster.org/ and by ESEfinder 3.0 software http://rulai.cshl.edu/cgibin/tools/ESE3/esefinder.cgi.

Screening for larger rearrangements was performed with the SALSA Multiplex Ligation-dependent Probe Amplification (MLPA) P093-B1 HHT/PPH1 probe mix kit (MRC-Holland BV, Amsterdam, The Netherlands).

The mutation nomenclature refers to the NCBI human BMPR2 nucleotide sequence (NCBI: NM_001204) and is expressed following the standard recommendations of the Association for Molecular Pathology Training and Education Committee [19] with the A of the ATG start codon denoted as +1 and the initiator methionine as codon 1.

\section{Results}

\section{Study Population}

Between January 2006 and December 2009 in total 262 patients agreed to participate in the study and EDTAblood has been stored for genetic analysis. Thirty-one patients had to be excluded due to several reasons. In 23 patients the further diagnostic work-up revealed a 
non-idiopathic form of pulmonary hypertension. In 3 patients the clinical data have been incomplete and in another 5 patients not enough blood for genetic analysis has been obtained. Thus, the study group for a complete genetic work-up consisted of 231 patients. All investigated patients were of Caucasian origin. About $91 \%$ of the analysed patients included in this study were of German ancestry, $4.8 \%$ were sent from different European countries (as Spain, Belgium, Netherlands, Sweden, Italy, and Eastern Europe), 1.3\% were of Arabian ancestry and $2.6 \%$ of Turkish ancestry.

\section{Genetic disposition to $\mathrm{PAH}$ in the study population}

Of the $231 \mathrm{PAH}$ index patients 22 (9.5\%) revealed a confirmed familial aggregation of the disease with at least one further affected family member. The remaining 209 patients $(90.5 \%)$ with negative family history have been classified as sporadic IPAH cases (Figure 1). In 49 patients of the $231 \mathrm{PAH}$ index patients $(21.2 \%)$ including 19 of the 22 familial $(86.4 \%)$ and in 30 of the 209 $(14.4 \%)$ apparently sporadic cases, mutations in the $B M P R 2$ gene have been identified (Figure 1).

\section{Clinical and hemodynamic characteristics}

The mean age at diagnosis of all 231 patients was 43.49 \pm 12.75 years; 168 patients were females reflecting a female to male ratio of 2.7:1. BMPR2 mutation carriers were significantly younger at diagnosis than non-carriers (Table 1). In three families without any identified mutation in BMPR2, ACVRL1, ENG, or SMAD8 the mean age at diagnosis $(27.3 \mathrm{y} \pm 4.78)$ was significantly lower than that of the mutation carriers and non-carriers (HPAH: $38.53 \mathrm{y} \pm 12.38$ and IPAH: $45.78 \mathrm{y} \pm 11.32, \mathrm{p}<$ $0.01)$, respectively. Since the mutation carrier status could not be clarified in these families they have been excluded for the genotype-phenotype comparison (Figure 1). Gender distribution was slightly but not significantly different in the mutation carriers (female/male ratio 1.9:1) and non-carriers (ratio $3: 1$, table 1 ).

BMPR2 mutation carriers had a significantly higher mean pulmonary artery pressure (mPAP) and pulmonary vascular resistance (PVR), and a significantly lower cardiac index (CI) than non-carriers (Table 1). Both groups did not significantly differ in WHO-functional class, oxygen saturation, heart rate, pulmonary capillary

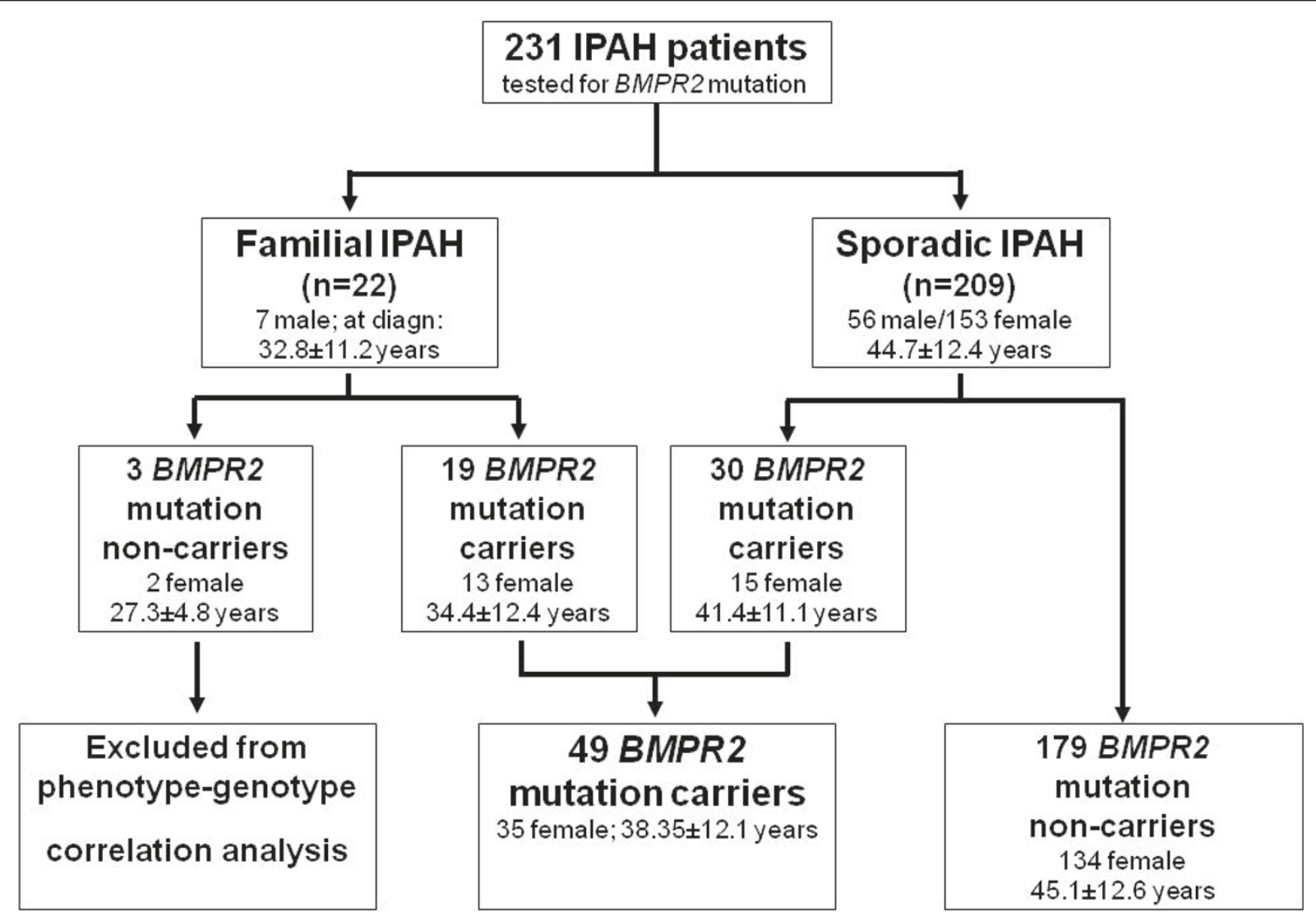

Figure 1 Genetic disposition of the study population. PAH = pulmonary arterial hypertension, IPAH = idiopathic PAH. The figure shows the proportion of BMPR2 mutation carriers in the study population, female to male proportion and the mean age at diagnosis. 
Table 1 Clinical characteristics at diagnosis

\begin{tabular}{|c|c|c|c|c|c|}
\hline \multirow[b]{2}{*}{ Patients } & \multirow[t]{2}{*}{ t-test } & \multicolumn{4}{|c|}{$\begin{array}{c}n=228 \\
43.49 y \pm 12.75\end{array}$} \\
\hline & & \multicolumn{2}{|c|}{$\begin{array}{c}\text { Mutation carrier } \\
\mathrm{n}=49\end{array}$} & \multicolumn{2}{|c|}{$\begin{array}{l}\text { Mutation non carrier } \\
n=179\end{array}$} \\
\hline Age at onset (years) & $* *$ & \multicolumn{2}{|c|}{38.53 y \pm 12.38} & \multicolumn{2}{|c|}{45.78 y \pm 11.32} \\
\hline female/male (ratio) & & \multicolumn{2}{|c|}{$32 / 17(1.9: 1)$} & \multicolumn{2}{|c|}{$134 / 45(3: 1)$} \\
\hline NYHA at diagnosis & & \multicolumn{2}{|c|}{$\mathrm{III-IV}$} & \multicolumn{2}{|c|}{ II-IV } \\
\hline \multicolumn{6}{|c|}{ Pulmonary hemodynamic parameters } \\
\hline Heart rate per minute & * & $83.57 \pm 11.79$ & $n=28$ & $77.38 \pm 9.07$ & $\mathrm{n}=88$ \\
\hline $\mathrm{SaO}^{2}(\%)$ & & $92.85 \pm 3.06$ & $n=26$ & $92.68 \pm 3.29$ & $\mathrm{n}=83$ \\
\hline PASP $(\mathrm{mm} \mathrm{Hg})$ & * & $98.5 \pm 16.35$ & $n=26$ & $87.73 \pm 18.78$ & $\mathrm{n}=83$ \\
\hline PADP $(\mathrm{mm} \mathrm{Hg})$ & & $44.5 \pm 7.5$ & $n=26$ & $36.37 \pm 9.22$ & $\mathrm{n}=81$ \\
\hline$\overline{m P A P}(\mathrm{~mm} \mathrm{Hg})$ & $* * *$ & $62.63 \pm 9.92$ & $n=35$ & $53.44 \pm 12.18$ & $\mathrm{n}=135$ \\
\hline PCWP & & $7.08 \pm 3.16$ & $n=26$ & $7.75 \pm 2.42$ & $\mathrm{n}=83$ \\
\hline$\overline{S A S P}(\mathrm{~mm} \mathrm{Hg})$ & * & $118.11 \pm 14.34$ & $n=27$ & $128.13 \pm 18.59$ & $\mathrm{n}=86$ \\
\hline $\operatorname{SADP}(\mathrm{mm} \mathrm{Hg})$ & & $76.5 \pm 11.81$ & $n=27$ & $76.67 \pm 10.60$ & $\mathrm{n}=86$ \\
\hline Cl (Litres $\left./ \mathrm{min} / \mathrm{m}^{2}\right)$ & $* * *$ & $1.67 \pm 0.25$ & $n=31$ & $2.10 \pm 0.53$ & $n=124$ \\
\hline PVRI & $* * *$ & $2306.53 \pm 770.33$ & $n=25$ & $1503.25 \pm 671.76$ & $n=116$ \\
\hline$\overline{P V R}$ & $* * *$ & $1519.65 \pm 374.65$ & $n=22$ & $1000.36 \pm 456.51$ & $\mathrm{n}=71$ \\
\hline
\end{tabular}

wedge pressures (PCWP), and systemic arterial systolic (SASP) and diastolic (SADP) blood pressures (Table 1).

No correlation was seen in our data between truncating or missense mutation and sex, age of onset, and hemodynamic measurements (data not shown).

\section{BMPR2 mutations (Table 2)}

In $49 \mathrm{HPAH}$ patients heterozygous alterations (46 mutations and 3 unclassified variants) in the BMPR2 gene were identified; 12 mutations and 3 unclassified variants have been detected for the first time in this study (Table 2, Figure 2). Table 2 lists all identified sequence alterations, the type of alteration, their location in the gene, and the age at diagnosis. New identified mutations or unclassified variants of the BMPR2 gene are indicated by asterisks.

\section{Distribution and frequency of BMPR2 mutations}

The 49 BMPR2 mutation types identified in the study population were: 35 point mutations (21 nonsense mutations and 14 missense mutations), 4 splice site mutations (all with affected splice donor sites), 4 frameshift mutations (small deletions/insertions) and 6 large deletions. The nonsense and the frameshift mutations resulted in a premature termination of the protein. The mutations were distributed throughout the whole BMPR2 gene with two clusters in a) the extracellular domain (exons 2-4) and b) the serine/threonine protein kinase domain (exons 9-11). Four mutations occurred in more than one independent patient/family: p.R491W and p.R321X three times, respectively; p.C420Y, p. R873X and p.R899X two times, respectively.

In 8 of the 209 apparently sporadic cases BMPR2 mutations have been identified and subsequently, thorough analysis of their family members revealed the same mutation in further asymptomatic members (in 3 parents, 5 children, 2 siblings), indicating that the proportion of sporadic PAH has been over estimated.

\section{New mutations (Figure 2, Table 2)}

Five of the 12 identified, to the best of our knowledge not yet described BMPR2 mutations were nonsense mutations, 2 frameshift mutations, 2 larger deletions, 2 splice defects, and one missense mutation. The BMPR2 mutations have been identified in exon $2-3,6,10,11$, and 12 (Table 2, Figure 2).

Three of the identified 14 missense mutations are unclassified sequence variants (p.E386G, p.D487V and p.A154G) (Table 2 and 3). Their disease causing potential has not been clearly verified. Analysis of these variants by use of the program MutationTaster [20] showed that all three variants are predicted to be most likely disease causing mutations (Table 3). The p.E386G and the p.D487V variants were both located in the serine/threonine kinase domain which is a highly conserved region among different species and suggests an important role in the function and/or structure of this region whereas the p.A154G variant was located at the beginning of the transmembrane domain. The variants were additionally analysed with the program ESEfinder 
Table 2 Details of BMPR2 mutations

\begin{tabular}{|c|c|c|c|c|c|c|}
\hline Patient & new & $\begin{array}{l}\text { Mutation } \\
\text { Location } \\
\text { Exon }\end{array}$ & Nucleotide Change & Amino Acid Change & Mutation type & Age at diagnosis \\
\hline K6628 & & 1 & c.?_-540_76_?del & Del aa1-25? & Deletion & $50 y$ \\
\hline K4808 & & 1 & c.?_-540_76_?del & Del aa1-25? & Deletion & $23 y$ \\
\hline K9063 & & 1 & c. $48 \mathrm{G}>\mathrm{A}$ & p.W16X & Nonsense & $14 \mathrm{y}$ \\
\hline K4518 & * & 2 & $c .91 \mathrm{G}>\mathrm{T}$ & p.E31X & Nonsense & $45 y$ \\
\hline K4452 & $*$ & 2 & c. $244 C>T$ & p.Q82X & Nonsense & 39 y \\
\hline K1893 & * & $2-3$ & Del c.77?-c.418? & & Deletion & $27 y$ \\
\hline K7369 & & 3 & c. $353 C>T$ & p.C118Y & Missense & 56 y \\
\hline K15016 & & 3 & c. $377 \mathrm{~A}>\mathrm{G}$ & p.N126S & Missense & $28 \mathrm{y}$ \\
\hline K14629 & & 3 & c. $377 \mathrm{~A}>\mathrm{G}$ & p.N126S & Missense & 61 y \\
\hline K7341 & & 3 & c.?_248-c.418_?del & & Deletion & 31 y \\
\hline K2878 & * & Intron 3 & $c .418+5 G>A$ & & Splice defect & $25 y$ \\
\hline K14983 & & 4 & c. $439 \mathrm{C}>\mathrm{T}$ & p.R147X & Nonsense & $49 y$ \\
\hline K6834 & * & 4 & c. $461 C>G$ & p.A154G & Missense/unclassified variant & $33 y$ \\
\hline K7833 & & 4 & C.507 C > A & p.C169X & Nonsense & 41 y \\
\hline K2917 & $*$ & $4-13$ & Del c.419? - c.3017? & & Deletion & $30 \mathrm{y}$ \\
\hline K6565 & & 6 & c. $631 \mathrm{G}>\mathrm{A}$ & p.R211X & Nonsense & 51 y \\
\hline K6686 & * & 6 & c.660insG & p. G220fsX224 & Frameshift & $18 \mathrm{y}$ \\
\hline K14147 & & 6 & $\mathrm{c} .818 \mathrm{~T}>\mathrm{G}$ & p.M273R & Missense & 59 y \\
\hline K5429 & & 7 & C.961C > T & p.R321X & Nonsense & $27 \mathrm{y}$ \\
\hline K5633 & & 7 & C.961C > T & p.R321X & Nonsense & $50 y$ \\
\hline K12665 & & 7 & C.961C $>\mathrm{T}$ & p.R321X & Nonsense & 69 y \\
\hline K3771 & & Intron 8 & c. $1128+1 G>T$ & del aa323-425 & Splice defect & $40 y$ \\
\hline K7892 & * & 9 & c. $1157 A>G$ & p.E386G & Missense/unclassified variant & 52 y \\
\hline K8027 & & 9 & c. $1259 \mathrm{G}>\mathrm{A}$ & p.C42OY & Missense & 56 y \\
\hline K11314 & & 9 & c. $1258 \mathrm{~T}>\mathrm{C}$ & p.C420R & Missense & $28 \mathrm{y}$ \\
\hline K15582 & * & 10 & c. $1296 C>$ G & p.Y432X & Nonsense & $28 \mathrm{y}$ \\
\hline K15529 & & 10 & c. 1297 C > T & p.Q433X & Nonsense & 32 y \\
\hline K4690 & & 10 & c.1313-1316delCAGA & p.T438fs X472 & Frameshift & $43 y$ \\
\hline MHH09 & & 10 & c. $1348 \mathrm{C}>\mathrm{T}$ & p.Q450X & Nonsense & $44 y$ \\
\hline MHH52 & & 10 & c.1388insA & p.P463fsX470 & Frameshift & 52 y \\
\hline K5943 & & 10 & c. $1397 G>A$ & p.W466X & Nonsense & $47 y$ \\
\hline K14763 & * & Intron 10 & c. $1413+1 G>A$ & & Splice defect & $43 y$ \\
\hline K7816 & & Intron 10 & c. $1413+3 \mathrm{~A}>\mathrm{T}$ & p.G426fsX453 & Splice defect & $45 y$ \\
\hline K12666 & * & 11 & c. $1460 \mathrm{~A}>\mathrm{T}$ & p.D487V & Missense/unclassified variant & 42 y \\
\hline K6717 & & 11 & c. $1471 C>T$ & p.R491W & Missense & 70 y \\
\hline K6361 & & 11 & c. $1471 C>T$ & p.R491W & Missense & $40 y$ \\
\hline K6201 & & 11 & c. $1471 C>T$ & p.R491W & Missense & $30 y$ \\
\hline K11744 & & 11 & c. $1472 G>A$ & p.R491Q & Missense & $26 y$ \\
\hline K5590 & & 11 & c. $1483 C>T$ & p.Q495X & Nonsense & 35 y \\
\hline K7936 & * & 11 & c. $1523 G>A$ & p.W508X & Nonsense & $40 y$ \\
\hline K13356 & & $11-12$ & Del c.1414-? _2866+? & & Deletion & 17.25 y \\
\hline K10005 & * & 12 & c. $1598 \mathrm{~A}>\mathrm{G}$ & p.H533R & Missense & $26 y$ \\
\hline $\mathrm{MHH} 18$ & & 12 & c. $1750 \mathrm{C}>\mathrm{T}$ & p.R584X & Nonsense & $62 y$ \\
\hline K14424 & $*$ & 12 & c.2308delC & p.R770fsX771 & Frameshift & $29 y$ \\
\hline K12298 & & 12 & c. $2617 C>T$ & p.R873X & Nonsense & $50 y$ \\
\hline K12921 & & 12 & c. 2617 C > T & p.R873X & Nonsense & $53 y$ \\
\hline K13213 & * & 12 & c. $2626 C>T$ & p.Q876X & Nonsense & $26 y$ \\
\hline K8521 & & 12 & c. $2695 C>T$ & p.R899X & Nonsense & $34 \mathrm{y}$ \\
\hline K10327 & & 12 & c. $2695 \mathrm{C}>\mathrm{T}$ & p.R899X & Nonsense & $19 y$ \\
\hline
\end{tabular}

New identified mutations are indicated by asterisks (*) 


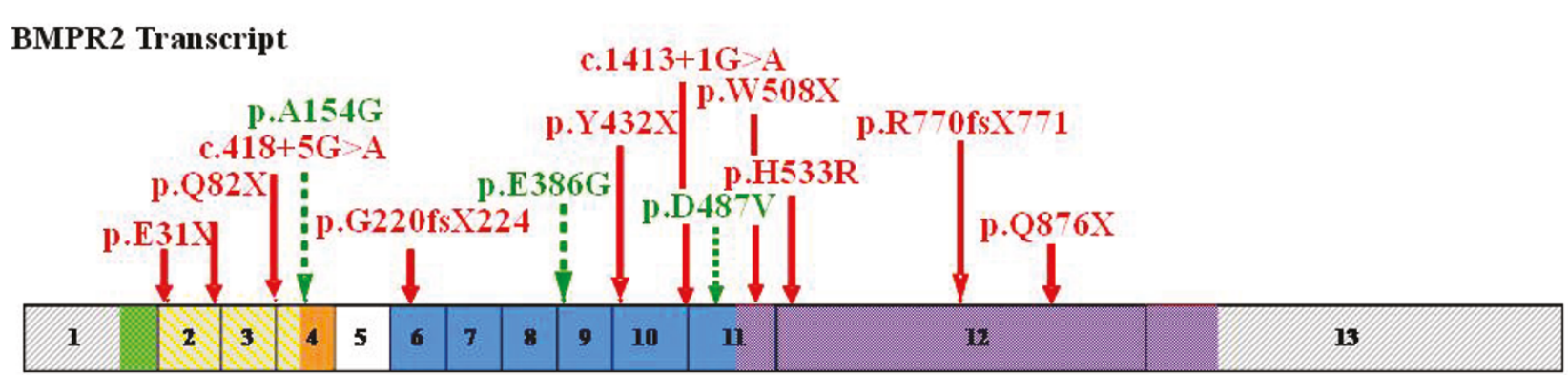

Del Ex2-3

Del Ex4-13

Signal peptide

Extracellular domain
Transmembrane domain

Serine/Threonine protein kinase domain

\section{Untranslated region $\downarrow$ New mutation \\ Cytoplasmic domain Unclassified variant}

Figure 2 Location of the new identified sequence alterations (mutations and/or unclassified variants). The figure shows the location of all newly identified mutations/unclassified variants through the BMPR2 transcript. Larger deletions are shown as line below the transcript, point mutations (nonsense and missense), splice site mutations and frameshift mutations are marked above the transcript as arrows, boxes represent exons, and colours of the boxes represent the different domains. Unclassified sequence alterations are highlighted in green and a dotted arrow. Mutations which are detected multiple times are only shown once. The mutations are widely distributed throughout the whole gene but two clusters are recognisable: cluster 1 lies in the extracellular domain (exons 2-4) whereas cluster 2 comprises exons 9 to 11 (serine/threonine protein kinase domain).

$[21,22]$ to investigate whether these substitutions might have an effect on exonic splicing. According to this analysis, the p.A154G and p.D487V variants had no effect on ESE binding sites whereas the p.E386G variant resulted in loss of 1 SF2/ASF- and 1 SRp40-site, respectively which might have an influence on the correct splicing [Table 3].

Clinical characterization of patients with familial PAH but no detectable mutation

Only in 3 out of the 22 families with HPAH (13.6\%, Figure 3) examination of the BMPR2 gene (promoter and coding regions including flanking intronic regions) and the coding regions of the ACVRL1, ENDOGLIN, and the $S M A D 8$ genes did not reveal any defect.
Especially, no point mutations or gross deletions/duplications were detectable.

In the affected members of all three families PAH has been diagnosed very early (mean age: $27.3 \mathrm{y} \pm 4.78$ ) and was characterised by a very severe and rapid progressive clinical phenotype (mean hemodynamic values of the index patients catheterization at diagnosis were: mPAP: $56.3 \pm 13.22 \mathrm{mmHg}$; PCWP: $7.7 \pm 2.05 \mathrm{mmHg}$; CI: 2.01 \pm 0.47 ; mean PVR $812 \pm 68$ dyn; heart rate $91.7 \pm 9.43$ beats/min). Although no mutations could be identified in the coding regions of the investigated genes there might be defects located in deeper intronic regions which could not be detected by conventional analysis methods or in other, until now, not identified genes participating in the BMPR2 signalling pathway.

Table 3 Analysis of the Unclassified BMPR2 Sequence Variants by use of computer prediction programs

\begin{tabular}{|c|c|c|c|c|c|}
\hline $\begin{array}{l}\text { Unclassified } \\
\text { variant }\end{array}$ & Localization & $\begin{array}{l}\text { MutationTaster } \\
\text { prediction }\end{array}$ & $\begin{array}{l}\text { Conservation across } \\
\text { different species }\end{array}$ & $\begin{array}{l}\text { ESEfinder } \\
\text { prediction }\end{array}$ & $\begin{array}{c}\text { Clinical classification according } \\
\text { to family history }\end{array}$ \\
\hline p.A154G & $\begin{array}{l}\text { Transmembrane } \\
\text { domain }\end{array}$ & Disease causing & conserved & Not affected & IPAH \\
\hline p.E386G & $\begin{array}{l}\text { Serine/threonine } \\
\text { kinase domain }\end{array}$ & Disease causing & conserved & $\begin{array}{l}\text { SF2/ASF-\& SRp40- } \\
\text { site affected }\end{array}$ & IPAH \\
\hline p.D487V & $\begin{array}{l}\text { Serine/threonine } \\
\text { kinase domain }\end{array}$ & Disease causing & conserved & Not affected & PAH with familial history \\
\hline
\end{tabular}




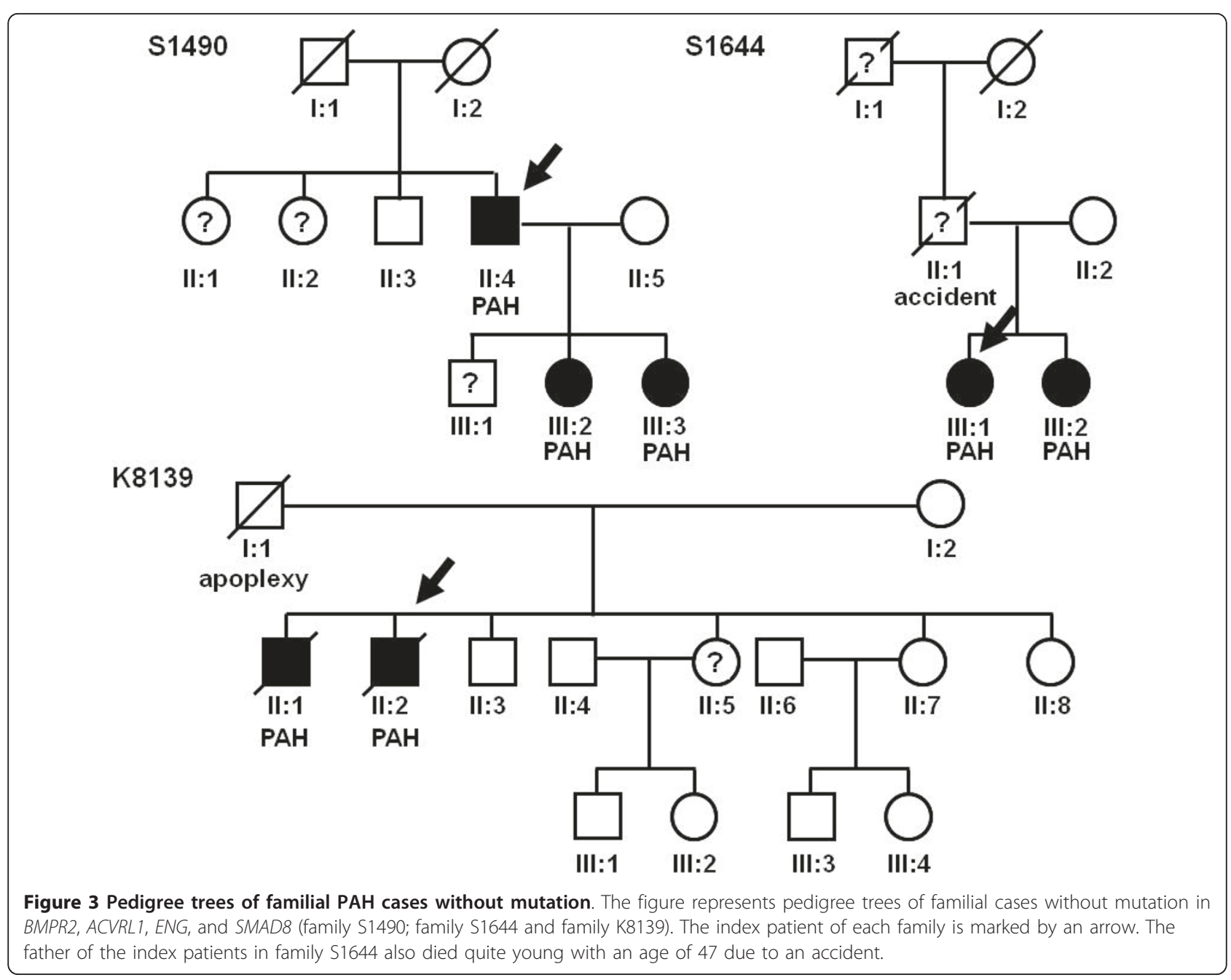

\section{Family S1490}

The male index patient (II:4) in this family presented first symptoms at age of 31 years and died early at an age of 33 years due to sudden right heart failure after an infection, two months after PAH was diagnosed. About 20 years later his children presented for familial screening assessment in Heidelberg. This analysis revealed a severe PAH in his two daughters (III:2, III:3). They have been early listed for double lung transplantation, which has been successfully performed 2 years after diagnosis.

\section{Family S1644}

The female index patient (III:1) of this family was invasively diagnosed at an age of 22 years. She was severely affected with NYHA class III, severely impaired right ventricular function and hemodynamic values (heart rate per min: 85; mPAP: $75 \mathrm{mmHg}$; PCWP: $8 \mathrm{mmHg}$; CI: 2.0). Her sister (III:2) died very young (age 22 years) because of PAH, no DNA sample was available. She had dyspnoea from early childhood on and was initially diagnosed as bronchial asthma although no asthma attacks had occurred. The father also died quite young with an age of 47 years because of an accident and could not be examined. No other family members showed signs of PAH. Sequence and MLPA analysis were both negative for mutations or deletion/duplication in all investigated genes (Figure 3).

\section{K8139A}

A rapid progressive clinical phenotype has been detected in this family as well. The male index patient (II:2) showed first symptoms of PAH at an age of 33 years which was finally confirmed by right heart catheterization at age of 34 years (heart rate per min: 105; pulmonary arterial systolic pressure: $68 \mathrm{mmHg}$; pulmonary arterial diastolic pressure: $36 \mathrm{mmHg}$; mPAP: $46 \mathrm{mmHg}$; PCWP: $5 \mathrm{mmHg}$; SASP: $85 \mathrm{mmHg}$; SADP: $60 \mathrm{mmHg}$; CI: 1.44; PVR: 744 dyn). He presented with NYHA class III-IV, severely impaired right ventricular function and died finally at the age of 38 years although he has 
received a triple $\mathrm{PH}$-specific therapy including intravenous prostacyclin. He had refused the listing for lung transplantation. His affected older brother (II:1) died also very young (age 26 years) because of PAH within three months after appearance of the first symptoms. No DNA sample was available from him. The father (I:1) died at age of 68 years due to an apoplexy. The familial screening assessment revealed no PAH in any other family member so far (Figure 3 ).

\section{Discussion}

In this study, we confirmed previous findings that BMPR2 mutation carriers are younger at diagnosis with a more severe hemodynamic compromise in a large prospectively assessed cohort of patients with confirmed PAH. Furthermore, we identified 12 to the best of our knowledge not yet described BMPR2 mutations and 3 unclassified sequence variants.

The study obtained BMPR2 mutations in $86.4 \%$ of $\mathrm{HPAH}$ patients with a positive family history and in $14.4 \%$ of patients with apparently sporadic disease. Only in 3 out of 22 families with confirmed HPAH (13.6\%) no genetic defect could be detected. This result suggests that with the increasing knowledge on BMPR2 sequence alterations and the improving diagnostic genetic techniques the rate of identifiable genetic defects in familial PAH might be even higher ( $>80 \%$ ) than previously suggested $(\approx 70 \%)[1,7]$.

\section{BMPR2 mutations and clinical phenotype}

Previous data indicated that having BMPR2 mutations is associated with a more aggressive form of PAH based on an earlier age at diagnosis and more severe hemodynamic [6,12-15]. Although survival was similar in mutation carriers and non-carriers, patients with BMPR2 mutation were more likely to be treated with parenteral prostacyclin therapy or to undergo lung transplantation [13]. Worse hemodynamic parameters [12] and reduced vasoreactivity $[6,12,14-16]$ have been described in PAHpatients with non-synonymous BMPR2 mutations. The study performed by Rosenzweig et al [12] included children and showed a significant lower cardiac index but no significantly higher mPAP or PVR. No significantly differences in the hemodynamic parameters of mutation carriers vs. non-carriers have been found by Dewachter et al [23]. They suggested this might be due to the small number of patients $(\mathrm{n}=28)$ in this study [23].

However, some studies have been retrospective in design. Our study has analysed the impact of BMPR2 mutations on the age at diagnosis and hemodynamic parameters for the first time in a prospective design and confirms the findings of the previous studies $[6,12,14,15]$.

Due to the limited number of patients carrying a BMPR2 mutation most studies do not allow to sufficiently correlate distinct mutation types with clinical presentation. Austin et al. [17] showed that PAH patients carrying a truncating mutation in the BMPR2 gene developed a more severe disease than patients without truncating mutation. No correlation was seen in our data between truncating mutation and gender, age of onset, and hemodynamic values. This is in concordance with the results of the French PAH registry [15].

Since occurrence of BMPR2 mutations obviously influences the clinical phenotype genetic testing may become of increasing clinical relevance. Patients with BMPR2 mutation tend to a more severe clinical phenotype and might be followed more closely. Clinical assessment of family members $[11,24]$ might be therefore especially of importance in patients with detected mutations.

\section{Identification of new BMPR2 mutations}

In this study we identified different types of mutations resulting in a truncated protein which might all interfere with the downstream signalling of the BMP pathway (for example by nonsense mediated decay) and activate proliferating pathways [25]. The detected BMPR2 mutations were distributed throughout the whole gene with 2 clusters as described previously $[1,6,15]$. Cluster 1 was located in the extracellular domain (exons 2-4) whereas cluster 2 comprised exons 9 to 11 (serine/threonine protein kinase domain). As a consequence the complete gene should be genetically analysed in clinical routine.

From 49 mutations 12 were newly identified and were predominantly nonsense mutations. Three newly found missense mutations were termed unclassified variants because their disease causing potential has not been clearly verified until now. Analysis of these variants by usage of different prediction programs showed that all three variants are predicted to be most likely disease causing mutations (Table 3). Two of them (p.E386G and p.D487V) are located in the serine/threonine kinase domain which is a highly conserved region among different species and suggests an important role in the function and/or structure of this region whereas the third (p.A154G) variant is located at the beginning of the transmembrane domain. Therefore, all three variants are predicted to have an impact on the proper function of the protein.

\section{PAH families without BMPR2 mutation}

Three of the 22 familial PAH cases without mutation in the BMPR2 gene investigated in our study did not reveal defects of the ACVRL1 gene, the ENG gene, and the SMAD8 gene. We have excluded them from genotypephenotype analysis to reduce the risk of misclassification as has been described before [15]. Interestingly, mean age at diagnosis in this small group was even significantly lower as in all other patients. Girerd and 
collegues [14] described this for patients with familial $\mathrm{PAH}$ and hereditary hemorrhagic telangiectasia carrying a mutation in the $A C V R L 1$ gene. In our families hereditary hemorrhagic telangiectasia and ACVRL1 gene defects have been excluded. The proportion of patients with familial aggregation but no detectable BMPR2 mutation was in our study even lower (13.6\%) than in other cohorts $(17.6 \%$ in the study performed by Austin et al. and $26.3 \%$ in the French registry, respectively $[6,17])$. Consequently, it may be assumed that mutations in the known genes $B M P R 2$, Activin A receptor type IIlike 1, Endoglin, and SMAD8 are not the only cause of the disease. However, in our 3 BMPR2 negative PAH families it is alternatively possible that these patients carry mutations in intronic or regulatory regions, which have not been detected by the used standard techniques.

Thus, in patients with familial aggregation of PAH $B M P R 2$ mutations are most likely. Genetic testing including the complete $B M P R 2$ gene may improve risk stratification in all patients with $\mathrm{PAH}$.

\section{Acknowledgements and Funding}

The study was funded by a grant of the European Union in the 6th Framework, "Pulmotension"

\section{Author details}

${ }^{1}$ Centre for Pulmonary Hypertension Thoraxclinic, University of Heidelberg, Heidelberg, Germany. ${ }^{2}$ Institute of Human Genetics, University of Heidelberg, Germany. ${ }^{3}$ University of Giessen Lung Centre, Giessen, Germany.

${ }^{4}$ Department of Pneumology, University of Graz, Graz, Austria.

\section{Authors' contributions}

JSH and $\mathrm{KH}$ carried out the molecular genetic studies. NP carried out the molecular genetic studies, drafted the manuscript and evaluated the molecular genetic data. CF performed the statistical analysis and drafted the manuscript. NE, CN, HT, HO, FR, AHAG and EG treated the patients and collected data. EG and WS conceived of the study, and participated in its design and coordination and drafted the manuscript. All authors read and approved the final manuscript.

\section{Competing interests}

The authors declare that they have no competing interests.

Received: 2 March 2011 Accepted: 29 July 2011 Published: 29 July 2011

\section{References}

1. Machado RD, Eickelberg O, Elliott CG, Geraci MW, Hanaoka M, Loyd JE, Newman JH, Phillips JA, Soubrier F, Trembath RC, Chung WK: Genetics and genomics of pulmonary arterial hypertension. J Am Coll Cardiol 2009, 54: S32-42.

2. Galie N, Hoeper MM, Humbert M, Torbicki A, Vachiery JL, Barbera JA, Beghetti M, Corris P, Gaine S, Gibbs JS, et al: Guidelines for the diagnosis and treatment of pulmonary hypertension. Eur Respir J 2009, 34:1219-1263.

3. Aldred MA, Vijayakrishnan J, James V, Soubrier F, Gomez-Sanchez MA, Martensson G, Galie N, Manes A, Corris P, Simonneau G, et al: BMPR2 gene rearrangements account for a significant proportion of mutations in familial and idiopathic pulmonary arterial hypertension. Hum Mutat 2006, 27:212-213.

4. Koehler R, Grunig E, Pauciulo MW, Hoeper MM, Olschewski H, Wilkens $H_{\text {, }}$ Halank M, Winkler J, Ewert R, Bremer H, et al: Low frequency of BMPR2 mutations in a German cohort of patients with sporadic idiopathic pulmonary arterial hypertension. J Med Genet 2004, 41:e127.
5. Elliott CG: Genetics of pulmonary arterial hypertension: current and future implications. Semin Respir Crit Care Med 2005, 26:365-371.

6. Sztrymf B, Coulet F, Girerd B, Yaici A, Jais X, Sitbon O, Montani D, Souza R, Simonneau G, Soubrier F, Humbert M: Clinical outcomes of pulmonary arterial hypertension in carriers of BMPR2 mutation. Am J Respir Crit Care Med 2008, 177:1377-1383.

7. Austin ED, Loyd JE, Phillips JA: Genetics of pulmonary arterial hypertension. Semin Respir Crit Care Med 2009, 30:386-398.

8. Trembath RC, Thomson JR, Machado RD, Morgan NV, Atkinson C, Winship I, Simonneau G, Galie N, Loyd JE, Humbert M, et al: Clinical and molecular genetic features of pulmonary hypertension in patients with hereditary hemorrhagic telangiectasia. N Engl J Med 2001, 345:325-334.

9. Chaouat A, Coulet F, Favre C, Simonneau G, Weitzenblum E, Soubrier F, Humbert M: Endoglin germline mutation in a patient with hereditary haemorrhagic telangiectasia and dexfenfluramine associated pulmonary arterial hypertension. Thorax 2004, 59:446-448.

10. Shintani M, Yagi H, Nakayama T, Saji T, Matsuoka R: A new nonsense mutation of SMAD8 associated with pulmonary arterial hypertension. $J$ Med Genet 2009, 46:331-337.

11. Grunig E, Weissmann S, Ehlken N, Fijalkowska A, Fischer C, Fourme T, Galie N, Ghofrani A, Harrison RE, Huez S, et al: Stress Doppler echocardiography in relatives of patients with idiopathic and familial pulmonary arterial hypertension: results of a multicenter European analysis of pulmonary artery pressure response to exercise and hypoxia. Circulation 2009, 119:1747-1757.

12. Rosenzweig EB, Morse JH, Knowles JA, Chada KK, Khan AM, Roberts KE, McElroy JJ, Juskiw NK, Mallory NC, Rich S, et al: Clinical implications of determining BMPR2 mutation status in a large cohort of children and adults with pulmonary arterial hypertension. J Heart Lung Transplant 2008, 27:668-674.

13. Humbert M, Sitbon O, Chaouat A, Bertocchi M, Habib G, Gressin V, Yaici A, Weitzenblum E, Cordier JF, Chabot F, et al: Pulmonary arterial hypertension in France: results from a national registry. Am J Respir Crit Care Med 2006, 173:1023-1030.

14. Girerd B, Montani D, Coulet F, Sztrymf B, Yaici A, Jais X, Tregouet D, Reis A, Drouin-Garraud V, Fraisse A, et al: Clinical outcomes of pulmonary arterial hypertension in patients carrying an ACVRL1 (ALK1) mutation. Am J Respir Crit Care Med 2010, 181:851-861.

15. Girerd B, Montani D, Eyries M, Yaici A, Sztrymf B, Coulet F, Sitbon O, Simonneau G, Soubrier F, Humbert M: Absence of influence of gender and BMPR2 mutation type on clinical phenotypes of pulmonary arterial hypertension. Respir Res 2010, 11:73.

16. Elliott CG, Glissmeyer EW, Havlena GT, Carlquist J, Mckinney JT, Rich S, McGoon MD, Scholand MB, Kim M, Jensen RL, et al: Relationship of BMPR2 mutations to vasoreactivity in pulmonary arterial hypertension. Circulation 2006, 113:2509-2515.

17. Austin ED, Phillips JA, Cogan JD, Hamid R, Yu C, Stanton KC, Phillips CA Wheeler LA, Robbins IM, Newman JH, Loyd JE: Truncating and missense BMPR2 mutations differentially affect the severity of heritable pulmonary arterial hypertension. Respir Res 2009, 10:87.

18. Phillips JA, Poling JS, Phillips CA, Stanton KC, Austin ED, Cogan JD, Wheeler L, Yu C, Newman JH, Dietz HC, Loyd JE: Synergistic heterozygosity for TGFbeta1 SNPs and BMPR2 mutations modulates the age at diagnosis and penetrance of familial pulmonary arterial hypertension. Genet Med 2008, 10:359-365.

19. Ogino S, Gulley ML, den Dunnen JT, Wilson RB: Standard mutation nomenclature in molecular diagnostics: practical and educational challenges. J Mol Diagn 2007, 9:1-6.

20. Schwarz JM, Rodelsperger C, Schuelke M, Seelow D: MutationTaster evaluates disease-causing potential of sequence alterations. Nat Methods 2010, 7:575-576.

21. Smith PJ, Zhang C, Wang J, Chew SL, Zhang MQ, Krainer AR: An increased specificity score matrix for the prediction of SF2/ASF-specific exonic splicing enhancers. Hum Mol Genet 2006, 15:2490-2508.

22. Cartegni L, Wang J, Zhu Z, Zhang MQ, Krainer AR: ESEfinder: A web resource to identify exonic splicing enhancers. Nucleic Acids Res 2003, 31:3568-3571.

23. Dewachter L, Adnot S, Guignabert C, Tu L, Marcos E, Fadel E, Humbert M, Dartevelle P, Simonneau G, Naeije R, Eddahibi S: Bone morphogenetic protein signalling in heritable versus idiopathic pulmonary hypertension. Eur Respir J 2009, 34:1100-1110. 
24. Grunig E, Janssen B, Mereles D, Barth U, Borst MM, Vogt IR, Fischer C, Olschewski H, Kuecherer HF, Kubler W: Abnormal pulmonary artery pressure response in asymptomatic carriers of primary pulmonary hypertension gene. Circulation 2000, 102:1145-1150.

25. Takahashi H, Goto N, Kojima Y, Tsuda Y, Morio Y, Muramatsu M, Fukuchi Y: Downregulation of type II bone morphogenetic protein receptor in hypoxic pulmonary hypertension. Am J Physiol Lung Cell Mol Physiol 2006, 290:L450-458.

doi:10.1186/1465-9921-12-99

Cite this article as: Pfarr et al: Hemodynamic and clinical onset in patients with hereditary pulmonary arterial hypertension and BMPR2 mutations. Respiratory Research 2011 12:99.

Submit your next manuscript to BioMed Central and take full advantage of:

- Convenient online submission

- Thorough peer review

- No space constraints or color figure charges

- Immediate publication on acceptance

- Inclusion in PubMed, CAS, Scopus and Google Scholar

- Research which is freely available for redistribution

Submit your manuscript at www.biomedcentral.com/submit 